\section{Vietnam Journal of Agricultural Sciences}

Received: April 6, 2019 Accepted: July 31, 2020

\section{Correspondence to}

nguyenphuongle@vnua.edu.vn

\section{ORCID}

Do Kim Chung

https://orcid.org/0000-0002-2100-

5607

Nguyen Phuong Le

https://orcid.org/0000-0002-14243754

\title{
Education, Employment, and Income: An Overview of Rural-Urban Gaps in Vietnam
}

\author{
Nguyen Phuong Le \& Do Kim Chung \\ Faculty of Economics and Rural Development, Vietnam National University of \\ Agriculture, Hanoi 131000, Vietnam
}

\begin{abstract}
Since the time of Doi Moi, the Vietnamese government has implemented a variety of policies to foster more balanced economic growth and development between rural and urban sectors. Several government policies that have been enacted were in the fields of agricultural reform and rural development. However, uneven development between urban and rural areas still exists. Based on secondary data, this study shows the urban-rural gaps in terms of education, employment, and income. The paper points out that the higher the level of education a person attains, the more considerable the disparities between urban and rural inhabitants can be observed. This fact strongly influences the occupations and incomes of urban as well as rural workers. The recommended policies to reduce the gaps between urban and rural areas include enhancing credit access for rural people, particularly to the poor; improving access to education and job training opportunities for formal sector employment; and entrepreneurial support to start household businesses, which all serve to increase income opportunities for low-income groups in the rural sector.
\end{abstract}

\section{Keywords}

Rural-urban gap, education, employment, income

\section{Introduction}

The transition to a market economy in Vietnam began in 1986, following the enactment of Doi Moi (renovation), which was a major package of economic reforms that led to a series of changes in socioeconomic policies. A number of strategies and programs concerning rural development and poverty reduction, including a national targeted program on poverty reduction, socio-economic development programs, and a special program of new countryside development, have been promulgated. Together with these mentioned programs and as a member of the United Nations, Vietnam has adopted the 2030 Agenda for Sustainable Development that pledges to ensure "no one will be left behind" and to "endeavor to reach the furthest behind first" (UNDP, 2015). Thanks to these development program implementations, Vietnam has made significant achievements in increasing the value of its gross national product, controlling the population growth rate, raising living 
standards, and especially, reducing poverty. The income and living standards of rural people have been continuously improving. In the period of 2008-2017, the average income per capita/year in rural areas increased 3.5 times (from 9.15 million to 32 million VND). Similarly, in the period of 2012-2017, the average household income in rural areas increased sharply from 75.8 million to nearly 130 million VND (Dao The Anh \& Nguyen Van Bo, 2019). However, the disparities between rural and urban areas continue to exist in Vietnam even though the income gap has narrowed from 2.1 times in 2008 to 1.8 times in 2017 (Dao The Anh \& Nguyen Van Bo, 2019). The question is why do the disparities still exist and in what aspects? According to World Bank (2004), the urban areas of Vietnam benefit from their initial advantages of geographical location, infrastructure characteristics, and industrial clustering, and thus, have become growth centers attracting foreign investments. In contrast, rural areas are viewed as relatively inefficient and by-passed by development.

Many studies on rural-urban inequality in Vietnam have focused mainly on income or expenditure differences by applying different quantitative methods (Nguyen et al., 2007; Le \& Fesselmeyer, 2008; Le \& Booth, 2010). But the gaps between rural and urban areas should be clearly seen in two terms: First, defining rural and urban coverage that strongly determines ruralurban disparities, and secondly, taking into account both economic and social aspects such as education, employment, and poverty. It has been argued that educational level plays an important part in human resource development, particularly a laborers' knowledge and skills. Therefore, the differences in educational achievements between rural and urban residents strongly influence their job opportunities and thus, their income and poverty. Based on this argument, the focus of this paper is to analyze the rural-urban disparities in terms of education, employment, and then income. Through the findings, recommendations are drawn in order to narrow the gap between rural and urban regions in terms of education, employment, and living standards.

\section{Methodology}

All the data used in the paper were secondarily collected from different sources such as the General Statistics Office and the Vietnam Household Living Standards Survey (VHLSS) database within 5 years from 2015 to 2019 . The collected data were analyzed by the comparative method. Comparisons were made by time and by region in terms of literacy rates, net enrolment rate of children at the right age for school, highest educational level, rate of trained laborers, employment status, income per capita, expenditures per capita, poverty rate, and the Gini coefficient.

\section{Results and Discussions}

\section{Rural-urban definition in Vietnam}

As previously mentioned, rural and urban coverage strongly determines rural-urban gaps. In order to investigate the gaps between the rural and urban sectors, it is necessary to define "rural" and "urban". The problem of defining "rural" or "urban" is not new. People know whether they are rural or urban, but such perception does not satisfy demographers, policymakers, or researchers. The definition of rural/urban areas significantly varies from one country to another. Consequently, one can hardly compare particular rural areas without any precise common definition.

In Hungary, for instance, the official definitions of urban and rural areas are legacies from the socialist era and depend on a statutory distinction between "urban settlements", the localities that have been entitled with an "urban" status, and "rural settlements", the ones that have no such title. This distinction was theoretically built on the examination of the urban functions of a settlement and a minimum threshold of 5,000 inhabitants. But many exceptions can be found, such as the deliberate promotion of certain villages during socialist times so that some "cities" have a total of 1,400 inhabitants while some rural settlements have as many as 12,000 inhabitants, and still have not been promoted to a city. Therefore, such an administrative definition is quite heavy to update and does not sufficiently reflect the current territorial structures of the country. Many periurban settlements, whose public utilities and economic functions are provided by the central city, have not been included in official urban agglomerations. The areas surrounding Budapest, for instance, appear among the most "rural" areas 
of the country, which one can seriously doubt (Depraz, 2018).

According to Singh (2003), the term rural means an area that is characterized by a non-urban style of life, occupational structure, social organization, and settlement pattern. By Blakely's (1984) view, major features previously used to define rural (simple life, agriculture, smallness, homogeneity, and dullness) fail to describe much of rural America. Instead, a rural area is increasingly defined by examining numerous broad categories of information. Deavers \& Brown (1985) developed seven categories of rural areas based on social, demographic, and economic information. The economic categories include agriculture, manufacturing, mining, and government; the social dimensions include persistent poverty and growth of the retired population; and the proportion of land in federal ownership comprises the final category. Horn (1985) looked at values, socio-economic factors, political structure, locus of control, and priorities for schools. Noting that other authors propose occupational, ecological, and sociocultural definitions, Whitaker (1982) also supported complex and multidimensional definitions.

In Vietnam, the urban classification system was established in 2001 and updated in 2009 with the inception of Decree No. 42/2009/ND-CP (Box 1). According to this decree, urban is an area where living residents concentrate with high density and operate primarily in non-agriculture economy, the center of politics, administration, economy, culture or profession, with the role of promoting economic and social development of the country or a region of territory or a locality, including the inner city, suburbs of the city, inner town and outskirts of towns; and townships (Vietnam Government, 2009). It is a hierarchical system constituted by six classes of urban centers that are defined by different levels of economic activities, physical development, population, population density, and infrastructure provision. Moreover, combinations of both urban and non-urban areas in each administrative unit exist. This means that there are rural communes in towns and even in cities and vice versa. Thus, rural can be defined as an area without indicators to be considered urban. According to Decree No. 57/2018/ND-CP, a "rural area refers to an administrative division, excluding areas situated in the vicinity of award of a district-level town, district, or city" (Vietnam Government, 2018).

The urban-rural classification system is dynamic as the Vietnam government reclassifies cities and rearranges communes. As a result, numerous cities, districts, and communes in Vietnam change from time to time. As shown in Table 1, by the end of 2017, Vietnam was divided into 63 managed provinces and cities (five central cities and 58 provinces and cities); 713 administrative units at the district level (districts, towns, and provincial managed cities); and more than 11,000 communes, quarters, and towns of districts. In comparison with 2016 data, the total

\section{Box 1: Indicators to be considered as urban areas in Vietnam}

\footnotetext{
1. Population of an urban center is at least 4,000 .

2. The population density suits the size, nature and characteristics of each urban center grade and is calculated for the inner area or township's consolidated street quarter. This means each urban class requires different population densities and the density is calculated with the inner areas of the total urban area (including both the rural and urban areas).

3. Non-agricultural labor within the inner area or consolidated street quarter accounts for $65 \%$ or more of total.

4. Urban infrastructure facilities, including social infrastructure facilities and technical infrastructure facilities: For inner areas, these facilities are built in a synchronous manner and completed to an extent prescribed for each urban class. For suburbs and outskirts, infrastructure networks are built in a synchronous manner, satisfying environmental protection and sustainable urban development requirements.

5. Urban architecture and landscape: Urban construction and development comply with Approved Regulations on Urban Architecture Management (ARUAM). An urban center has model urban quarters, civilized urban streets and public areas for its inhabitants' spiritual life; and has typical architectural complexes or works suitable to its environment and natural landscape.
}

Source: Decree No. 42/2009/ND-CP (Vietnam Government, 2009). 
Table 1. Number of administrative units as of December 31, 2017 by region

\begin{tabular}{cccccccc}
\hline Region & $\begin{array}{c}\text { Cities under } \\
\text { province }\end{array}$ & $\begin{array}{c}\text { Urban } \\
\text { districts }\end{array}$ & Towns & $\begin{array}{c}\text { Rural } \\
\text { districts }\end{array}$ & Wards & $\begin{array}{c}\text { Town } \\
\text { districts }\end{array}$ & Communes \\
\hline Whole country & 71 & 49 & 48 & 545 & 1,596 & 607 & 8,959 \\
Red River Delta & 14 & 19 & 5 & 92 & 442 & 118 & 1,898 \\
Northern midlands and mountainous areas & 15 & 0 & 4 & 122 & 145 & 139 & 2,282 \\
North Central and Central coastal areas & 16 & 6 & 15 & 137 & 340 & 145 & 2,431 \\
Central Highlands & 5 & 0 & 4 & 53 & 77 & 50 & 599 \\
$\quad$ South East & 6 & 19 & 8 & 39 & 380 & 35 & 457 \\
Mekong River Delta & 15 & 5 & 12 & 102 & 212 & 120 & 1,292 \\
\hline
\end{tabular}

Source: General Statistics Office (2017).

units did not change, the number of urban units (cities under provinces, wards, and town districts) increased, and the number of communes decreased.

According to the General Statistics Office (GSO, 2019), by the middle of 2019, Vietnam's population was 96.2 million, ranked $14^{\text {th }}$ in the world, and was divided into six socio-economic regions, of which the most populous region is the Red River Delta (more than 21.5 million people), followed by the North Central Coast (20.05 million people), and the Mekong River Delta with 17.8 million people. The least populated areas are the Northern midlands and mountainous areas (12.3 million people) and the Central Highlands with about 5.9 million people. The proportion of the total population classified as urban is increasing year by year. Based on statistical data, the number of people considered to be part of the urban population and the proportion of the total population changed from 26.5 million people (30.5\% of the population) in 2010 to 33.8 million people (35.7\%) in 2018 (as shown in Table 2).

Rapid and widespread urbanization in the last decade has sparked urban population growth. The average population growth rate in urban areas in the period of 2009-2019 was $2.62 \%$ per year, nearly 6 times higher than the growth rate in rural areas $(0.44 \%$ per year). Although the pace of urbanization in Vietnam has increased rapidly in recent years, the proportion of the population living in urban areas remains low compared to other nations in Southeast Asia, and is only higher than that of East Timor (30.6\%), Myanmar (30.6\%), and Cambodia (23.4\%) (Statista.com, 2018). The differences between rural and urban regions are not only clear in terms of administrative units, population composition, and governmentsupported policies, but also in other aspects such as infrastructure for living and production, electricity, and freshwater. The following sections analyze the gaps between rural and urban regions in education, job opportunities, and income.

\section{Educational attainment in rural and urban areas}

According to the 2005 Education Law, the state will ensure education accessibility for everyone, while giving priorities to ethnic minorities and other disadvantaged groups. Primary education is compulsory for all children. The Education Law articulates that "the State exerts unified management of the national educational system concerning the objectives, programs, content, and plans of education, the criteria of teachers, the regulations on examinations, and the system of diplomas". The law also makes it clear that the state budget holds a key role in the total education investment (Vietnam National Assembly, 2005). Before 2017, the proportion of annual budget expenses for education and training in Vietnam was approximately $20 \%$, equivalent to $5 \%$ of the GDP. In comparison with other countries in the region, the proportion of public budget expenses for education and training in Vietnam is higher, even compared to more developed countries such as Singapore, Malaysia, Thailand, and South Korea (Phung Van Hien, 2018). 
Table 2. Distribution of population by sex and region

\begin{tabular}{ccccccc}
\hline & \multicolumn{9}{c}{ Unit: Percent } \\
\cline { 2 - 6 } Categories & 2015 & 2016 & 2017 & 2018 & 2019 \\
& 33.88 & 33.44 & 35.04 & 35.74 & 34.40 \\
Urban & 66.12 & 65.56 & 64.96 & 64.26 & 65.60 \\
Rural & 49.31 & 49.36 & 49.39 & 49.42 & 49.55 \\
Male & 50.69 & 50.64 & 50.61 & 50.48 & 50.45
\end{tabular}

Source: General Statistics Office (2018) and Central Population and Housing Census (2019).

Table 3. Literacy rates for the population aged 15 and older by sex and region

\begin{tabular}{|c|c|c|c|c|c|}
\hline \multirow{2}{*}{ Categories } & \multicolumn{5}{|c|}{ Year } \\
\hline & 2015 & 2016 & 2017 & 2018 & 2019 \\
\hline Whole country & 94.9 & 95.0 & 95.1 & 94.8 & 95.8 \\
\hline Urban & 97.6 & 97.7 & 97.8 & 97.7 & 98.3 \\
\hline Rural & 93.5 & 93.6 & 93.6 & 93.2 & 94.3 \\
\hline Male & 96.6 & 96.6 & 96.7 & 96.5 & 97.0 \\
\hline Female & 93.3 & 93.5 & 93.6 & 93.2 & 94.6 \\
\hline
\end{tabular}

Source: General Statistics Office (2018) and Central Population and Housing Census (2019).

Apart from budget funding, the government has also expressed a strong commitment and succeeded in its approach towards renovating the national educational system, leading the movement to improve learning and teaching equality, and upgrading school facilities and creating better learning environments. Thanks to the reforms in educational policies, Vietnam has achieved universal primary education and the country is moving towards universal lower secondary education. According to data from the General Statistics Office, the literacy rate for the population aged 15 and older is almost 100\% in both urban and rural areas. However, the rates for male and urban groups are still higher than for female and rural ones (as shown in Table 3). Due to compulsory primary education and illiteracy elimination efforts and policies, the gap in literacy rates in these two areas has gradually narrowed in recent years to a discrepancy of 4.0 percentage points, lower than the 4.7 percentage-point gap in 2009 (Central Population and Housing Census, 2019).

Together with a high literacy rate, the enrolment rates of children at the right age for school enrolment are quite high, particularly at primary school. By 2014, the net enrolment rate for primary education reached $93.0 \%$, and net enrolment rates for lower secondary education and upper secondary were $84.4 \%$ and $63.1 \%$, respectively. Table 4 shows that the universalization of primary education has been achieved in nearly every district, and the rates of primary school enrolment for the rural sector were very similar to the rates for the urban sector. Further, it is recognized that the differences in the enrolment rates between the urban and rural sectors at higher levels of education are clear and consistent over the years. The urban-rural gap is even wider for upper secondary education enrolment than for lower secondary.

Compared to 2010, the 2019 net school enrolment rates at lower secondary and upper secondary schools increased considerably (almost $10 \%$ in rural areas), but the gap at these levels of schooling between rural and urban regions are still relatively large. The highest gross and net school attendance rates in lower and upper secondary schools were in the Red River Delta region and the lowest rates were in the Mekong River Delta region. The gap in the net school attendance rate between the two regions was 28.4 percentage points for upper secondary school and 12.5 percentage points for lower secondary school. This implies that more effort should be devoted to 
Table 4. Net enrolment rates of children at the right age for school enrolment

\begin{tabular}{|c|c|c|c|c|}
\hline \multirow{2}{*}{ Criteria } & \multicolumn{4}{|c|}{ Year } \\
\hline & 2010 & 2012 & 2014 & 2019 \\
\hline \multicolumn{5}{|l|}{ Whole country } \\
\hline Primary & 91.9 & 92.4 & 93.0 & 98.0 \\
\hline Lower Secondary & 81.3 & 81.4 & 84.4 & 89.2 \\
\hline Upper Secondary & 58.2 & 59.4 & 63.1 & 68.3 \\
\hline \multicolumn{5}{|l|}{ Urban } \\
\hline Primary & 92.8 & 92.6 & 93.6 & 98.3 \\
\hline Lower Secondary & 86.0 & 85.0 & 88.9 & 91.6 \\
\hline Upper Secondary & 69.6 & 70.2 & 73.2 & 76.4 \\
\hline \multicolumn{5}{|l|}{ Rural } \\
\hline Primary & 91.6 & 92.4 & 92.8 & 97.9 \\
\hline Lower Secondary & 79.7 & 80.1 & 82.7 & 88.1 \\
\hline Upper Secondary & 54.4 & 55.6 & 59.3 & 64.4 \\
\hline
\end{tabular}

Source: VHLSS (2014) and Central Population and Housing Census (2019).

increasing school attendance in the Mekong River Delta.

Table 5 shows urban-rural differentials in educational attainment. The largest differential is at the highest education level; the proportion of the urban population that completed upper secondary and higher education was over two times higher than among the rural population $(50.1 \%$ for urban areas and $23.4 \%$ for rural areas). Particularly, members of the urban population holding college, university, and higher degrees were almost four times higher than rural residents. In contrast, the proportion of the rural population that completed primary education was higher in rural areas $(24.3 \%)$ than in urban areas $(16.5 \%)$.

Dang Kim Khoi \& Tran Cong Thang (2019) pointed out that although there still exists a big gap in education between rural and urban areas in higher levels, the educational attainment of the young rural generation has significantly improved. The percentage of rural people who have no certificate has reduced from $22.7 \%$ in 2004 to $10.3 \%$ in 2016. Additionally, the percentage of rural people who have finished upper secondary level and above was $34.7 \%$ in 2016, which was twice as high compared to 2004.

As economic conditions have improved, rural families now pay more attention and invest more in their children's education. The number of young people who go to vocational colleges and universities has increased. The percentage of rural people completing college and university is still much lower than in urban areas. As a consequence, the rate of trained laborers aged 15 and older in rural areas is also much lower in comparison with urban areas. For instance, this rate was three times higher in urban areas than in rural areas in 2018 (Table 6).

Aside from these achievements, two of the biggest issues faced by the nation nowadays are inequality in the accessibility of education and variations in the quality of education that still exist between the majority and ethnic minority communities, between remote or mountainous and easily assessable communities, and between rural and urban areas. The universalization of primary education has been achieved in nearly every district, and the rates of primary school enrolment for the rural sector were very similar to those of the urban sector. The urban-rural gap can be seen more clearly at the higher educational levels. Particularly, the percentage of people who obtained upper secondary, primary vocational, and university education in urban areas is much higher 
Table 5. Proportion of the population aged 15 and older by the highest educational level and region

\begin{tabular}{cccc}
\hline & & & Unit: Percent \\
\hline Highest educational level & Total & Urban & 6.6 \\
\hline Never go to school & 5.3 & 2.4 & 15.4 \\
No certificate & 13.2 & 8.5 & 24.3 \\
Primary & 21.8 & 16.5 & 30.4 \\
Lower secondary & 27.9 & 22.5 & 12.5 \\
Upper secondary & 14.5 & 18.7 & 2.3 \\
Primary vocational & 3.0 & 4.6 & 1.4 \\
Secondary apprentice & 1.8 & 2.8 & 0.3 \\
College vocational & 0.4 & 0.6 & 2.4 \\
Professional secondary & 3.1 & 4.8 & 4.4 \\
College, university & 8.5 & 17.4 & 0.1 \\
Postgraduate & 0.4 & 1.2 & 100 \\
Total & 100 & 100 & 2.4 \\
\hline
\end{tabular}

Source: VHLSS (2014).

Table 6. Rate of trained laborers aged 15 and older by sex and region

\begin{tabular}{cccccc}
\hline \multirow{2}{*}{ Categories } & \multicolumn{3}{c}{ Unit: Percent } \\
\cline { 2 - 6 } & 2014 & 2015 & 2016 & 2017 & 2018 \\
\hline Whole country & 18.2 & 19.9 & 20.6 & 21.4 & 21.9 \\
Urban & 34.3 & 36.3 & 37.2 & 37.9 & 38.0 \\
Rural & 11.2 & 12.6 & 12.8 & 13.7 & 14.3 \\
Male & 20.4 & 22.4 & 23.0 & 24.0 & 24.4 \\
Female & 15.8 & 17.3 & 18.0 & 18.7 & 19.5 \\
\hline
\end{tabular}

Source: General Statistics Office (2018).

than those in rural areas. This disparity can largely be explained by the underdeveloped infrastructure and poor services in rural communities, especially in remote areas.

\section{Rural-urban employment differences}

The quality of education is a major determining factor in promoting productivity, and fostering economic growth and social development. Education is vital in the context of Vietnam's high level of integration in the global context. The role of education has become increasingly important as it equips people with the necessary skills and knowledge to embrace an increasingly fast-growing economy.

Table 7 shows that rural laborers are employed more often than urban ones. In Vietnamese rural areas, an occupation pattern is more diversified than in the urban area. A rural laborer can work as both a farmer and a carpenter, vendor, or construction worker. Therefore, the percentage of laborers who are unemployed in rural areas is lower than in urban. At the same time, the unemployment rate is relatively low and has decreased throughout the whole country, but with a significant difference between the urban and rural areas. In 2018, the unemployment rate in urban areas was $3.1 \%$, while it was $1.73 \%$ in rural areas. In other words, urban employment is more vulnerable than rural employment. The proportion of informal workers was estimated at 59\% in urban areas and $35 \%$ in rural areas in 2016 (Dang Kim Khoi \& Tran Cong Thang, 2019). By contrast, the percentage of trained workers who are employed in urban areas is three times higher than the percentage in rural areas. This explains why many rural laborers decide to migrate to the cities and most of them work as unskilled workers and in informal sectors. 
Table 7. Employment status of the population aged 15 and older by region and year

\begin{tabular}{|c|c|c|c|c|c|}
\hline \multirow{2}{*}{ Region } & \multicolumn{5}{|c|}{ Year } \\
\hline & 2014 & 2015 & 2016 & 2017 & 2018 \\
\hline \multicolumn{6}{|c|}{ Annual employed population aged 15 and older } \\
\hline Whole country & 58.1 & 57.6 & 57.5 & 53.7 & 54.3 \\
\hline Urban & 53.3 & 52.6 & 52.9 & 52.1 & 51.8 \\
\hline Rural & 60.5 & 60.2 & 59.9 & 60.1 & 60.3 \\
\hline \multicolumn{6}{|c|}{ Unemployment rate } \\
\hline Whole country & 2.10 & 2.33 & 2.30 & 2.24 & 2.19 \\
\hline Urban & 3.40 & 3.37 & 3.23 & 3.18 & 3.10 \\
\hline Rural & 1.49 & 1.82 & 1.84 & 1.78 & 1.73 \\
\hline \multicolumn{6}{|c|}{ Trained employed workers } \\
\hline Whole country & 18.2 & 19.9 & 20.6 & 21.4 & 21.9 \\
\hline Urban & 34.3 & 36.3 & 37.2 & 37.9 & 38.0 \\
\hline Rural & 11.2 & 12.6 & 12.8 & 13.7 & 14.3 \\
\hline
\end{tabular}

Source: General Statistics Office (2018)

Three decades ago, Vietnam's 1989 census recorded very few internal migrants. The majority moved from one rural location to another, and their motives for relocating were a mix of economic and other factors (Dang, 1999). Ten years later, 4.5 million people changed their working residences in the five-year interval from 1994 to 1999 . By this time, the economic reform era was well underway, and the surge in spontaneous migration was driven far more explicitly by income differentials (Phan \& Coxhead, 2010). By the next census in 2009, this five-year migration figure had increased by almost $50 \%$, to 6.6 million (Marx \& Fleischer, 2010), or almost $8 \%$ of the total population. Vietnam's economic growth since the early 1990s has been dominated by secondary and tertiary sectors, with immense contributions from foreign investments and the reform of state-owned enterprises, especially in the Mekong River Delta, South East, Northern midlands, and Red River Delta regions. Therefore, there was a similar migration flow movement from rural to urban sectors in these regions which occupied more than $40 \%$ of the total migrant population (Table 8). Dang Kim Khoi \& Tran Cong Thang (2019) showed that the urban to urban movement mostly happened in the Northern Central and Central coastal regions, while rural to rural movement was the popular trend in the Central Highlands.
According to the 2019 census, in the period from 2009 to 2019, the number of employed workers positively shifted towards reducing the labor proportions in the agriculture, forestry, and fishery sectors, and increasing labor shares in the industry and construction, and services sectors. The proportion of employed laborers in the agriculture, forestry, and fishery sectors has been continuously decreasing over the past 10 years, from $53.9 \%$ in 2009 to $46.3 \%$ in 2014 and $35.3 \%$ in 2019. Particularly, among the three sectors, 2019 was the first year to show the highest proportion of employees working in the services sector (agriculture, forestry, and fishery sector: $35.3 \%$; industry and construction: $29.2 \%$, and services: $35.5 \%$ ). Regarding the relationship between occupation and educational level, the 2019 census also revealed that most rural laborers working in the farming-related sectors have low educational levels such as "never go to school", "no certificate", and primary school. Further, most of them belong to poor households that mainly rely on agriculture.

\section{Urban-rural income gaps}

Employment is the most important factor that directly impacts the living standards of the population through its role in household income generation. This section investigates the 
disparity between the urban and rural sectors based on both per capita household income and per capita household expenditures.

According to the data in Table 9, during the period from 2014 to 2018, both urban and rural income per capita per month increased 1.4 times (at the current VND value). Nevertheless, the absolute value difference between rural and urban income per capita per month has not narrowed, instead, it seems to be widening. For example, in 2014, urban residence income was 3964 thousand VND while the rural counterpart was 2038 thousand VND (equal to 1.94 times), a difference of 1926 thousand VND. In 2018, the difference was 2633 thousand VND (equal to 1.9 times).

As mentioned in the previous section, the occupational structures of both rural and urban laborers have become more diversified since the 1990s. As a result, households' income sources are diversified. Data collected by different surveys including the census and VHLSS showed that the numbers of households' income sources have increased with time, especially in rural areas. According to Dang Kim Khoi \& Tran Cong Thang (2019), the number of rural households that have more than two income sources outside agriculture increased from 52\% in 2002 to $60 \%$ in 2016. Data in Table 10 indicate that income per capita per month from the agricultural sector decreased from $28.75 \%$ in 2014 to $22.68 \%$ in 2018 in rural areas, while income per capita per month from nonfarming sectors rapidly increased. In particular, salary and wages per capita in rural areas in 2018 increased by $46.7 \%$ as compared to 2014 .

Although the income structure in 2018 changed considerably compared to the income structure of the previous years, the rate of increase of non-farming income in the urban areas is greater than in the rural. The proportion of income from the agricultural, forestry, and fishery sectors decreased, but it still occupied a large proportion of the total income of a rural resident. At the same time, the total income per capita in urban areas is almost twice (1.9 to 1.95 times) that of the rural areas. Urban households earn more than rural ones because they have better initial endowments, particularly infrastructure, education, and services, and they Receive higher returns on household endowments such as education and experience.
Apart from income, the households' expenditures and expenditure per capita are important indicators to assess real living standards in urban as well as in rural areas. Table 11 shows that the total monthly expenditure per capita have increased in the period of 2014-2018 at similar rates in the rural and urban areas (32.8 and 33.8\%, respectively). Nevertheless, the total monthly expenditure per capita have increased in the period of 2014-2018 at similar rates in the rural and urban areas (32.8 and $33.8 \%$, respectively). Nevertheless, the total monthly expenditure per capita in the urban areas was 1.7 times higher than in the rural area. It shows a tendency of a shortening gap in comparison with the past decade. For example, in 2006 and 2008, the total monthly expenditures per capita in the urban area were twice as high than in the rural areas. Rural households consume less than their urban counterparts because the cost of living is lower in rural areas, and the consumption of home-produced goods may sometimes not be counted as expenditures for rural households.

In general, the biggest expenses for all the households were living expenses with the rates of 94\% in the urban areas and $92 \%$ in the rural areas. This proves that the living standard has improved more and more because the households do not have to spend too much on daily life but on other purposes in order to satisfy their own needs. Looking at the structure of living expenses, it can be seen that both the urban and rural residents spend less and less on eating and drinking expenditures. The rate of decrease in urban areas was faster than in rural areas, particularly the urban residents' non-eating and drinking expenditures increased from $49.6 \%$ in 2016 to $54.7 \%$ in 2018 , whereas the rural residents' proportions were 45.7 and $51.1 \%$, respectively.

Among the non-eating and drinking expenditures, according to Dang Kim Khoi \& Tran Cong Thang (2019), rural annual spending per capita for education occupied a small proportion and tended to decrease over time (4.7\% in 2002 and $3.9 \%$ in 2016). One important reason is the fact that the government's expenditure on education have increased almost 1.6 times during the period from 2013 to 2018. Further, most of the state budget is spent on early childhood education, and primary, secondary, and high schools (89\%). While the proportion of a household's expenditure for education decreased, the absolute value of annual 
Education, employment, and income: An overview of rural-urban gaps in Vietnam

Table 8. Migration flows by socio-economic region and year

\begin{tabular}{|c|c|c|c|c|c|c|c|c|c|c|c|c|c|c|c|}
\hline \multirow{2}{*}{ Region } & \multicolumn{3}{|c|}{ In-migration rate } & \multirow[b]{2}{*}{2017} & \multirow[b]{2}{*}{2018} & \multicolumn{4}{|c|}{ Out-migration rate } & \multicolumn{6}{|c|}{ Net-migration rate } \\
\hline & 2014 & 2015 & 2016 & & & 2014 & 2015 & 2016 & 2017 & 2018 & 2014 & 2015 & 2016 & 2017 & 2018 \\
\hline Whole country & 9.2 & 5.5 & 4.6 & 3.7 & & 9.2 & 5.5 & 4.6 & 3.7 & & & & & & \\
\hline Red River Delta & 3.1 & 1.8 & 1.7 & 1.3 & 2.1 & 3.6 & 1.8 & 1.2 & 1.3 & 1.4 & -0.5 & 0.0 & 0.5 & 0.0 & 0.8 \\
\hline Northern midlands and mountainous areas & 2.3 & 1.1 & 0.8 & 0.7 & 0.7 & 4.3 & 3.0 & 3.3 & 1.8 & 2.8 & -2.0 & -1.9 & -2.5 & -1.1 & -2.1 \\
\hline Central Highlands & 7.7 & 2.3 & 2.0 & 1.9 & 1.3 & 6.1 & 3.4 & 4.4 & 2.6 & 3.2 & 1.6 & -1.1 & -2.4 & -0.7 & -1.9 \\
\hline South East & 18.5 & 12.8 & 10.8 & 7.9 & 11.8 & 7.3 & 3.1 & 2.4 & 2.4 & 1.9 & 11.2 & 9.7 & 8.4 & 5.6 & 9.9 \\
\hline Mekong River Delta & 2.2 & 1.1 & 1.1 & 0.6 & 1.0 & 8.9 & 6.5 & 5.7 & 4.6 & 6.8 & -6.7 & -5.4 & -4.6 & -4.0 & -5.8 \\
\hline
\end{tabular}

Source: General Statistics Office (2018).

Table 9. Monthly income per capita by residence and year

Unit: 1000 VND (at the current value)

\begin{tabular}{ccccc}
\hline Region & & Year & \\
\cline { 2 - 4 } & Whole country & 2014 & 2016 & 3098 \\
Urban & 2637 & 4551 & 3876 \\
Rural & 3964 & 5623 & 2423 \\
Urban/Rural Ratio & 2038 & 1.87 & 1.89 \\
\hline
\end{tabular}

Source: General Statistics Office (2018). 
Table 10. Structure of monthly income per capita by income source and region

\begin{tabular}{|c|c|c|c|c|c|c|c|c|c|c|c|c|}
\hline \multirow{3}{*}{ Sources of income } & \multicolumn{4}{|c|}{2014} & \multicolumn{4}{|c|}{2016} & \multicolumn{4}{|c|}{2018} \\
\hline & \multicolumn{2}{|c|}{ Urban } & \multicolumn{2}{|c|}{ Rural } & \multicolumn{2}{|c|}{ Urban } & \multicolumn{2}{|c|}{ Rural } & \multicolumn{2}{|c|}{ Urban } & \multicolumn{2}{|c|}{ Rural } \\
\hline & $\begin{array}{c}\text { Qua } \\
\text { nt }\end{array}$ & $\%$ & $\begin{array}{c}\text { Qua } \\
\text { nt }\end{array}$ & $\%$ & $\begin{array}{c}\text { Qua } \\
\text { nt }\end{array}$ & $\%$ & $\begin{array}{c}\text { Qua } \\
\text { nt }\end{array}$ & $\%$ & $\begin{array}{c}\text { Qua } \\
\text { nt }\end{array}$ & $\%$ & $\begin{array}{c}\text { Qua } \\
\text { nt }\end{array}$ & $\%$ \\
\hline Total & $\begin{array}{c}396 \\
4\end{array}$ & 100.0 & $\begin{array}{c}203 \\
8\end{array}$ & 100.0 & 4551 & 100.0 & 2423 & 100.0 & 5623 & 100.0 & 2990 & 100.0 \\
\hline Salary and wages & $\begin{array}{c}222 \\
6\end{array}$ & 56.2 & 814 & 39.9 & 2537 & 55.7 & 999 & 41.2 & 3258 & 57.9 & 1333 & 44.6 \\
\hline $\begin{array}{l}\text { Agriculture, Forestry, } \\
\text { and Fisheries }\end{array}$ & 175 & 4.4 & 586 & 28.8 & 195 & 4.3 & 656 & 27.1 & 196 & 3.5 & 678 & 22.7 \\
\hline $\begin{array}{l}\text { Other than } \\
\text { Agriculture, Forestry, } \\
\text { and Fisheries }\end{array}$ & $\begin{array}{c}102 \\
9\end{array}$ & 25.9 & 393 & 19.2 & 1291 & 28.4 & 495 & 20.4 & 1429 & 25.4 & 605 & 20.2 \\
\hline Others & 534 & 13.5 & 245 & 12.1 & 528 & 11.6 & 273 & 11.3 & 740 & 13.2 & 375 & 12.5 \\
\hline
\end{tabular}

Source: General Statistics Office (2018).

educational expenditure per capita dramatically increased from 3.0 million VND in 2010 to 5.5 million VND in 2016, which is equivalent to $80.3 \%$ in rural areas. The gap between rural and urban areas in terms of educational expenditure per capita is widening. In 2016, urban annual educational expenditure per capita was twice that of rural areas, especially at higher education levels (GSO, 2019). The reason is the fact that most colleges and universities are located in big cities where the cost of living is high for a common rural resident. In many cases, educational investments become a burden for families.

Education and occupation have a direct impact on the employment and income of a household and thus, affect its poverty status. After analyzing the gaps between rural and urban areas in terms of education, employment, income, and expenditures, the last section of this paper focuses on the differences in poverty rates between urban and rural areas of Vietnam.

Vietnam is one of the best-performing nations on account of poverty reduction. The country has attained the Millennium Development Goals target on poverty reduction ahead of its schedule. Remarkable poverty reduction is the outcome of powerful economic growth, trade liberalization, and poverty reduction policies targeted directly at disadvantaged groups. The data in Table 12 show that poverty rates measured by income declined during 2014-2016 in the country as a whole, as well as in both urban and rural areas. However, the poverty rate in rural areas is much higher than in urban areas as well as the general rate. The trend of the poverty rate has changed since 2017 when the government adopted other poverty measurement methods. The multidimensions poverty (MDP) approach considers who is poor and is based not only on income and expenditures, but also on the disadvantages households are facing, such as living conditions, income levels, accessibilities to education, healthcare information, insurance, and social assistance. As a result, poverty rates in 2017 and 2018 increased, especially in rural areas.

According to UNDP (2019), the MDP rate is strongly correlated with the education level of the household head. The MDP rate of households headed by college or university graduates was just under $1 \%$, while those whose heads did not complete primary education was $26.6 \%$ in 2016 . The MDP rate fell among household groups by occupation of the household head. Households whose heads worked in the agricultural sector had the highest MDP rate, followed by unskilled labors. These groups also achieved poverty reduction during 2012-2016, but the rate of poverty reduction was lower than in other groups. Households whose heads were clerks, office workers, and skilled workers experienced the fastest MDP reduction rates.

Despite impressive achievements in poverty reduction, the country faces a number of challenges. The rate of poverty reduction varies across different ethnic groups and geographical regions. Poverty and low living standards are still prevalent in the remote and mountainous areas and 
in ethnic minority communities. The Northern midland and mountainous areas and the Central Highlands are among the regions that lag far behind the rest of the country in terms of poverty reduction. A proportion of households still fell back into poverty. Multidimensional poverty has become more apparent due to pressures from urbanization and migration. Low income is only one of several important aspects of poverty besides other deprivations in access to social services and access to basic living conditions.

The income gap between the rich and the poor is measured using the Gini coefficient ranging from 0 to 1 . There is no inequality if the Gini coefficient is 0 . When the level of inequality is higher, the value of the Gini coefficient also gets higher and when the Gini coefficient is 1 , there is absolute inequality.

The data in Table 13 present the Gini coefficients of Vietnam between 2010 and 2018. Inequality tends to move from the urban to the rural areas because the Gini coefficient in the urban areas tends to decrease (0.402 in 2010 and 0.372 in 2018) while it increases in the rural areas $(0.395$ in 2010 and 0.407 in 2018). The reason is that along with the development of science and technology, the explosion of information technology and the ability for all people to access information has improved. Workers in urban areas (usually trained and skilled) have more opportunities to find jobs and corresponding salaries. Meanwhile, in rural areas, people's access to information is still limited; the laborers are mostly unskilled or elderly. Therefore, they are less able to negotiate for their work as well as their wages as compared to those in the urban sector.

Regarding socio-economic regions, the Southeast region is currently the most equal in the country, while the Central Highlands and the Northern Midlands and Mountainous regions are the two most unequal areas. For the remaining regions, inequality does not tend to change significantly based on the Gini coefficients.

In summary, the gaps between rural and urban areas in terms of education, employment, and income exist throughout most of the country and the poor are still vulnerable. In the long term, the issues of the rural-urban gap and inequality need to be addressed and should be the targets of poverty reduction strategies. It is necessary to constantly promote and improve the effectiveness of rural development strategies and multidimensional poverty reduction policies which emphasize rural education and employment support. Moreover, all the support policies should have specific, transparent, detailed, and accessible guidelines so that individuals and organizations can grasp and implement them in accordance with specific conditions. Central and local governments should continue to promote the development of science and technology, to increase investments in education and training, to adopt important policies, and attract talents in order to improve living standards and public awareness about the ruralurban gap and inequality, and to upgrade human resources for sustainable development.

\section{Conclusion}

Since the time of Doi Moi (1986), Vietnam's government has implemented a variety of policies to foster a more even distribution of economic growth and rural development. Several government policies that promoted agricultural reforms such as land de-collectivization and price liberalization have contributed to ameliorating the disparity in income between the urban and rural sectors in Vietnam. In addition, the increasing importance of wage employment has not only reduced poverty but has also reduced inequalities within each sector. However, Vietnam has also suffered from problems associated with pro-urban policies in public finance, restrictions in labor mobility, and trade liberalization that have contributed to the development of the urban sector at the expense of the rural sector (Cao \& Akita, 2008). Based on secondary data, this study showed the ruralurban gaps in terms of education, employment, and income. The results found that the literacy rates of the population have increased in both the urban and rural areas for a decade. But, the net enrollment rates of school-aged children in the urban areas are higher than in the rural areas at all levels of universal education. With regard to the number of people who received high education degrees, the higher the level of education, the larger the disparity between urban and rural areas can be observed. This study also witnessed that the proportion of trained employed workers is relatively low in the country as a whole. Moreover, 
Nguyen Phuong Le \& Do Kim Chung (2020)

Table 11. Monthly average expenditure per capita by type, year, and region

Unit: 1000 VND (at the current value)

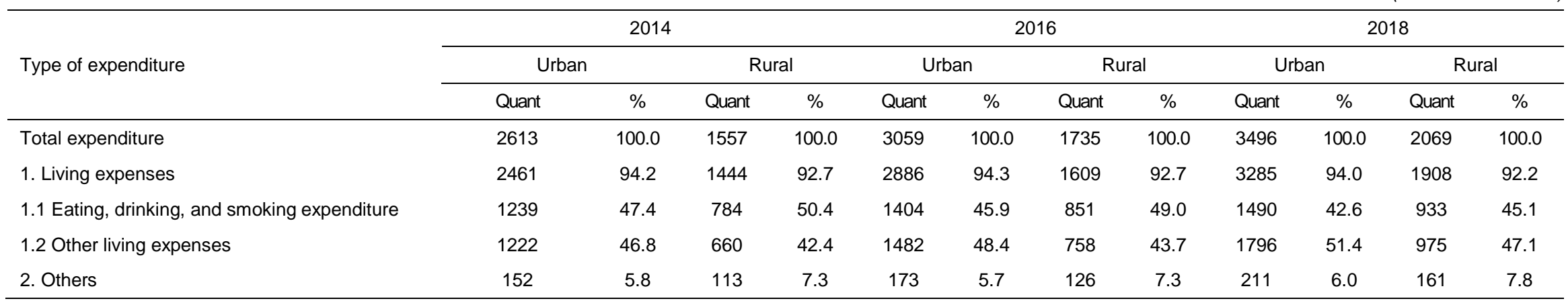

Source: General Statistics Office (2018).

Table 12. General poverty rates in Vietnam by region and year

\begin{tabular}{|c|c|c|c|}
\hline Year & Whole country & Urban & Rural \\
\hline 2014 & 8.4 & 3.0 & 10.8 \\
\hline 2015 & 7.0 & 2.5 & 9.2 \\
\hline 2016 & 5.8 & 2.0 & 7.5 \\
\hline $2017^{*}$ & 7.9 & 2.7 & 10.8 \\
\hline $2018^{*}$ & 6.8 & 1.5 & 9.6 \\
\hline
\end{tabular}

Note: $\left({ }^{*}\right)$ Multidimensions poverty rate.

Source: General Statistics Office (2018). 
Table 13. Gini coefficient by region and year

\begin{tabular}{cccccc}
\hline Regions & \multicolumn{5}{c}{ Year } \\
\cline { 2 - 6 } Urban & 2010 & 2012 & 2014 & 2016 & 2018 \\
Rural & 0.402 & 0.385 & 0.397 & 0.391 & 0.372 \\
Red River Delta & 0.395 & 0.399 & 0.398 & 0.408 & 0.407 \\
Northern midlands and mountainous areas & 0.408 & 0.393 & 0.407 & 0.401 & 0.392 \\
North Central area and Central coastal area & 0.406 & 0.411 & 0.416 & 0.433 & 0.443 \\
Central Highlands & 0.385 & 0.384 & 0.385 & 0.393 & 0.383 \\
South East & 0.408 & 0.397 & 0.408 & 0.439 & 0.440 \\
Mekong River Delta & 0.414 & 0.391 & 0.397 & 0.387 & 0.373
\end{tabular}

Source: General Statistics Office (2018).

the percentage of trained laborers working in urban areas is much higher than in rural areas. This has strong influences on occupation, and then the income of urban and rural workers. Although the unemployment rate in rural areas is less than in the urban areas, it does not demonstrate that rural residents have better employment statuses than their urban counterparts. The reason is the fact that a high percentage of the population aged 15 or older in urban areas mostly work in non-farm sectors while their rural counterparts mostly rely on farm activities. A number of rural laborers are facing situations of under-employment. Therefore, there has been an increase in the migration movement from rural to urban areas. Rural migrants to urban centers are usually members of low-income households that lack employment and/or agricultural land. When these migrants are employed in the urban sector, their remittances to their rural households help to increase the income of the poorer rural households, and then to reduce rural-urban income disparity.

With the aforementioned regards, this study recommends several policies that will help to reduce the gaps between urban and rural areas in terms of education, employment, and income such as providing access to credit for rural people, particularly to the poor; improving access to education and job training opportunities for formal sector employment; and entrepreneurial support to start household businesses, which all serve to increase income opportunities for low-income groups in the rural sector.

\section{References}

Blakely E. J. (1984). Rural Communities in an Advanced Industrial Society: Dilemmas and Opportunities. Retrieved on November 30, 2019 at https://eric.ed.gov/?id=ED247048.

Central Population and Housing Census (2019). The Vietnam Population and Housing Census: Implementation Organization and Preliminary Results. Statistical Publishing House: Hanoi (in Vietnamese).

Dang Kim Khoi \& Tran Cong Thang (2019). Picture of Vietnamese Farmer Livelihood in Integration Period (1990-2018). Agriculture Publishing House: Hanoi.

Dang N. A. (1999). Market Reforms and Internal Labor Migration in Vietnam. Asian and Pacific Migration Journal. 8(3): 381-409.

Dao The Anh \& Nguyen Van Bo (2019). Overview of Vietnam's Recent Agricultural and Rural Development Policy. Retrieved on December 30, 2019 at http://ap.fftc.agnet.org/ap_db.php?id=1017\&print=1 .

Deavers K. L. \& Brown D. L. (1985). Natural Resources Dependence, Rural Development, and Rural Poverty. Washington, DC: U.S. Department of Agriculture: 258 -775 .

Depraz S. (2018). Differentiating between Rural Areas: Indicators and Typologies. Retrieved on February 3, 2020 at https://halshs.archives-ouvertes.fr/halshs$01547488 v 2$.

Phan D. \& Coxhead I. (2010). Inter-provincial Migration and Inequality during Vietnam's Transition. Journal of Development Economics. 91(1): 100-112.

General Statistics Office (2017). Statistical Yearbook. Statistical Publishing House. Hanoi (in Vietnamese).

General Statistics Office (2018). Statistical Yearbook. Statistical Publishing House. Hanoi (in Vietnamese). 
General Statistics Office (2019). Statistical Yearbook. Statistical Publishing House. Hanoi (in Vietnamese).

Horn J. G. (1985). Recruitment and Preparation of Quality Teachers for Rural Schools. Manhattan, KS: Kansas State University: 258-785 (in Vietnamese).

Le H. T. \& Booth A. L. (2010). Inequality in Vietnamese Urban-Rural Living Standards, 1993-2006. Discussion Paper No. 4987. IZA, Bonn: Germany.

Le K. T. \& Fesselmeyer E. (2008). Rural Urban Gap in Vietnam: Semi-Parametric Decomposition and Urban Bias Policy Analysis, Working paper. Department of Economics, University of Virginia.

Marx V. \& Fleischer K. (2010). Internal Migration: Opportunities and Challenges for Socio-Economic Development in Vietnam. Hanoi, UNDP.

Nguyen B. T., Albrecht J. W., Vroman S. B. \& Westbrook M. D. (2007). A Quantile Regression Decomposition of Urban-Rural Inequality in Vietnam. Journal of Development Economics. 83(2): 466-490.

Phung Van Hien (2018). Public Investment in Education and Training in Vietnam. International Education Studies, Canadian Center of Science and Education. 11(7): 106-115.

Singh G. K. (2003). Administration for Rural Development Programs in India, Abhijeet Publication: 1-7, 68-101.

Statista.com (2018). Share of population in urban areas in Southeast Asian countries in 2018. Retrieved on March 12 , 2020

https://www.statista.com/statistics/616014/urbanpopulation-in-southeast-asia-by-country.

Cao T. C. V. \& Akita T. (2008). Urban and Rural Dimensions of Income Inequality in Vietnam. GSIR working papers. Economic Development \& Policy
Series EDP08-2. International Development Program, Graduate School of International Relations International University of Japan.

UNDP (2015). Transforming our world: The 2030 Agenda for Sustainable Development. Retrieved on January 15 , 2020 https://sustainabledevelopment.un.org/post2015/transf ormingourworld.

UNDP (2019). Multidimensional Poverty in Vietnam: Reducing Poverty in All its Dimensions to Ensure a Good Quality Life for All. Retrieved on March 3, 2020 at https://www.undp.org/content/dam/vietnam/docs/Public ations/MDP-full-E.pdf.

Vietnam Government (2009). Decree No. 42/2009/ND-CP on The Grading of Urban Centers. Dated May 7, 2009 (in Vietnamese).

Vietnam Government (2018). Decree No. 57/2018/ND-CP on Incentive Policies for Enterprises Investing in Agriculture and Rural Development Sector. Dated April 17, 2018.

Vietnam National Assembly (2005). Education Law. No. $38 / 2005 /$ QH11. Dated June $14^{\text {th }}, 2005$ (in Vietnamese).

VHLSS (2014). Vietnam Household Living Standards Survey. http://infodatavn.com/dieu-tra-vhlss (in Vietnamese).

Whitaker, W.H. (1982). "The Many Faces of Ephraim: In Search of Functional Typology of Rural Areas" in Rios, B.R.D. Rural-A Concept Beyond Definition?, Eric Digest-htm.

World Bank (2004). Issues and Dynamics: Urban Systems in Developing East Asia-Vietnam. East Asia Infrastructure Department. 